\title{
Caracterização etnobotânica dos sistemas de manejo de samambaia-preta (Rumohra adiantiformis (G. Forst) Ching - Dryopteridaceae) utilizados no sul do Brasil
}

\author{
Cristina Baldauf ${ }^{1}$, Natalia Hanazaki ${ }^{2}$ e Maurício Sedrez dos Reis ${ }^{1,3}$
}

Recebido em 22/09/2006. Aceito em 28/02/2007

\begin{abstract}
RESUMO - (Caracterização etnobotânica dos sistemas de manejo de samambaia-preta (Rumohra adiantiformis (G. Forst) Ching - Dryopteridaceae) utilizados no sul do Brasil). A samambaia-preta (Rumohra adiantiformis (G. Forst) Ching- Pteridophyta) é utilizada comercialmente na produção de arranjos florais. A extração desta espécie é fonte de renda de muitas famílias da região sul do Brasil. O objetivo deste estudo foi caracterizar os sistemas de manejo da espécie utilizados no Estado do Rio Grande do Sul (RS) através do uso de entrevistas semi-estruturadas e observação participante com famílias extrativistas do município de Maquiné-RS. Foi verificada a ocorrência de uma grande diversidade de técnicas de manejo, a partir da qual foi proposta uma tipologia de sistemas de manejo. A tipologia consiste em quatro sistemas de manejo principais, de acordo com o manejo da paisagem e das populações de samambaia empregados. Constatou-se uma associação entre a situação fundiária e os sistemas de manejo utilizados. Nas terras arrendadas é realizada apenas a coleta das frondes, enquanto nas terras próprias são realizadas intervenções como podas, derrubadas de árvores, retirada de frondes mortas, pisoteio da área após coleta, além de interação com sistemas de agricultura de coivara e criação de gado. A tipologia dos sistemas de manejo elaborada, em associação com outros estudos sobre a sustentabilidade do extrativismo de samambaia-preta, vem fundamentando a regulamentação desta atividade no Rio Grande do Sul.
\end{abstract}

Palavras-chave: manejo sustentável, extrativismo, samambaia-preta, produtos florestais não-madeireiros

\begin{abstract}
Ethnobotanical characterization of leatherleaf fern (Rumohra adiantiformis (G. Forst) Ching - Dryopteridaceae) management systems used in southern Brazil). The leatherleaf fern (Rumohra adiantiformis (G. Forst.) Ching) is commercially used in flower arrangements. The harvesting of this species is an income source for many families from southern Brazil. The aim of this study was to characterize species management systems used in Maquiné municipality, Rio Grande do Sul state (RS), through semi-structured interviews and participant observation with harvesters' families. A great diversity of management techniques was verified. Based on these management techniques, we propose a typology of the management systems. This typology consists in four main types of management systems, according to landscape management and leatherleaf fern population management used. An association between land tenure and the management system adopted was observed. On rented lands, only the fronds are harvested, while on private property harvesters use techniques such as trimming, tree-felling, removal of dead fronds, treading on the area after harvesting, and interaction with shifting cultivation and cattle. The typology of management systems presented here, in association with other studies on sustainability of leatherleaf fern harvesting, has provided support for the regulation/legalization of this activity in Rio Grande do Sul.
\end{abstract}

Key words: sustainable management, harvesting, leatherleaf fern, non-timber forest products

\section{Introdução}

A Mata Atlântica é um dos cinco ecossistemas de maior prioridade para conservação em escala mundial, apresentando elevada biodiversidade, alta taxa de endemismos e, ao mesmo tempo, grande perda de habitat e intensa pressão antrópica (Myers et al. 2000). Estima-se que vivem no entorno da Mata Atlântica, região de rico patrimônio étnico e cultural, aproximadamente 100 milhões de habitantes. Estes exercem enorme pressão sobre estes remanescentes, seja por espaço ou por seus recursos (Simões 2002).

Assim, é necessária a implementação de estratégias que permitam aliar as demandas de exploração dos recursos da Mata Atlântica com a conservação destes importantes remanescentes florestais. Uma destas estratégias é o manejo de populações naturais, o qual pode ser definido como a

\footnotetext{
1 Universidade Federal de Santa Catarina, Núcleo de Pesquisas em Florestas Tropicais, Laboratório de Ecologia Humana e EtnobotânicaUFSC/ ONG Anama, Centro de Ciências Agrárias, Núcleo de Pesquisas em Florestas Tropicais, Rodovia Admar Gonzaga 1346, Bairro Itacorubi, 88034-001 Florianópolis, SC, Brasil

2 Universidade Federal de Santa Catarina, Laboratório de Ecologia Humana e Etnobotânica, Centro de Ciências Agrárias, Campus Universitário Trindade, 88010-970 Florianópolis, SC, Brasil

3 Autor para correspondência: msreis@cca.ufsc.br
} 
exploração controlada das populações de uma dada espécie, visando à obtenção de um produto direto ou indireto (Reis 1996). O manejo de qualquer espécie em seu ecossistema exige a geração de conhecimentos sobre sua autoecologia, especialmente no que se refere à demografia e biologia reprodutiva (Reis et al.2000).

No entanto, toda sociedade humana acumula um acervo de informações sobre o ambiente que a cerca (Amorozo 1996). Desta forma, as comunidades que utilizam determinado recurso vegetal já possuem inúmeros saberes acerca dos ciclos da planta em questão, bem como dos aspectos que beneficiam ou desfavorecem a ocorrência de populações da espécie. Estes saberes são oriundos de experiências práticas através da vivência nos ecossistemas e podem complementar o conhecimento científico sobre o manejo de populações naturais (Berkes et al. 1998). Neste contexto, o manejo pode ser entendido como a gestão de um dado recurso baseada em um enfoque técnico-científico e/ou em práticas tradicionais (Diegues 2002).

Muitos dos trabalhos desenvolvidos até o momento em etnobiologia reforçam o importante conhecimento que os povos das florestas tropicais possuem acerca do ambiente onde vivem, sendo que estes conhecimentos abrangem não só um grande número de espécies úteis, mas também percepções sobre processos ecossistêmicos (Posey 1987; Balée 1994; Hanazaki et al. 2000). Entretanto, Diegues e Arruda (2001) destacam que grande parte dos trabalhos realizados ainda está concentrada nos sistemas de manejo tradicionais de populações indígenas, o que reforça a necessidade da realização de estudos com outros grupos culturais.

Uma vez que em ambientes tropicais as atividades de manejo de paisagens e populações naturais estão extremamente relacionadas às atividades agrícolas e de domesticação de plantas (Clement 1999), o estudo de grupos de tradição agrícola pode fornecer importantes subsídios para o estabelecimento de estratégias de conservação de um grande número de espécies, sobretudo de produtos florestais nãomadeireiros (PFNMs). O extrativismo de PFNM contribui para a subsistência da maioria absoluta dos agricultores familiares no Brasil hoje, tanto na Amazônia como no resto do país, sendo muitas vezes de fundamental importância para sua reprodução social (Clement 2006).

No Rio Grande do Sul as práticas extrativistas são, em muitos casos, decorrentes de um longo processo de empobrecimento de uma parte significativa de pequenos agricultores familiares locais em áreas de Mata No caso do Litoral Norte deste estado, o extrativismo de produtos florestais não-madeireiros, assim como a venda da força de trabalho como diaristas ou em empreitadas, tem permitido a manutenção de parte destes agricultores na região (Anama 2002).

Entre as décadas de 1960 e 1970 a mecanização da agricultura decorrente da "revolução verde" propiciou o desenvolvimento da horticultura nas áreas de várzea da região. Neste mesmo período os produtos agrícolas tradicionais como milho, feijão e mandioca, cultivados nas áreas de encosta, sofreram uma crescente desvalorização. Tais fatores provocaram declínio da agricultura tradicional na região, fundamentada no sistema de coivara, assim como contribuíram para a regeneração florestal nas áreas de encosta. Assim, ocorreu um grande êxodo rural no período, sendo que os agricultores familiares que permaneceram nas encostas não tinham muitas possibilidades de trabalho e geração de renda (Anama/ PGDR-UFRGS 2000).

Neste cenário, o surgimento do extrativismo de samambaia-preta (Rumohra adiantiformis (G. Forst) Ching) na década de 1970 representou uma importante alternativa econômica para as famílias agricultoras, a qual se expandiu nas décadas de 1980 e 1990 (Anama 2002). A samambaia-preta é utilizada mundialmente como folhagem na produção de arranjos florais, sendo que a grande preferência pela espécie decorre do fato de suas frondes apresentarem grande durabilidade após a coleta. A maior parte da produção mundial comercializada é oriunda da Flórida, onde a espécie é cultivada sob condições controladas (Milton \& Moll 1988). No Brasil, provavelmente mais da metade do mercado nacional é abastecido pelas folhas extraídas no Rio Grande do Sul, na quase totalidade das vezes através da extração direta em seu ambiente natural (Anama 2002).

Com o Decreto Federal $n^{\circ} 750$, de 10 de fevereiro de 1993, a continuidade do sistema da agricultura de coivara nas áreas de Mata Atlântica ficou ainda mais ameaçada, uma vez que este decreto proíbe o corte, a exploração e supressão de vegetação primária ou nos estádios avançado e médio de regeneração da Mata Atlântica. A partir de tal legislação, os órgãos fiscalizadores do RS passaram a agir com rigor nas áreas de pousio, multando os agricultores que derrubavam as capoeiras.

Neste contexto intensificou-se o extrativismo de samambaia-preta no Litoral Norte do Rio Grande do Sul, associado à redução da mão-de-obra na economia 
familiar, devido ao êxodo rural e às dificuldades no uso da terra impostas pela legislação ambiental (Anama 2002). Esta atividade possibilitou a permanência na terra dos agricultores familiares na região e a manutenção da organização social vinculada às relações familiares de produção. Concomitantemente ao aumento da importância do extrativismo na região, foram se desenvolvendo inúmeros saberes associados a esta prática.

Os objetivos deste trabalho foram a realização de uma caracterização etnobotânica do extrativismo de samambaia-preta no município de Maquiné, bem como a elaboração de uma tipologia dos sistemas de manejo utilizados a fim de fundamentar o processo de licenciamento da atividade extrativista na região de estudo. A hipótese central é a de que a diversidade de práticas utilizadas pelos extrativistas compõe diferentes sistemas de manejo da espécie no Litoral Norte do Rio Grande do Sul.

\section{Material e métodos}

Área de estudo - A região de estudo está situada na Bacia Hidrográfica do Rio Maquiné, cuja área aproximada é de $546 \mathrm{~km}^{2}$. Localiza-se entre as encostas da Serra Geral e a planície costeira do Rio Grande do Sul e pode ser subdividida em 14 sub-bacias principais: Água Parada, Pinheiro, Pavão, Escangalhado, Lajeado, Ouro, Ligeiro, Maquiné "Calha", Encantado, Solidão, Forqueta "Alto", Garapiá dos Severinos, Forqueta "Calha" e Garapiá dos Leões. A vegetação natural da bacia do rio Maquiné é constituída predominantemente por Floresta Ombrófila Densa, mas por situar-se em zona de transição fitogeográfica, apresenta também elementos de Floresta Estacional Semidecidual, Floresta Ombrófila Mista e Campos de Altitude (Sevegnani \& Baptista 1996). Atualmente a cobertura da terra na região é extremamente heterogênea, apresentando um mosaico de vegetação primária, vegetação secundária em diversos estádios de desenvolvimento e áreas agrícolas.

Segundo o censo do IBGE (2000), Maquiné possui uma população de aproximadamente 7.304 habitantes, dos quais 5.379 encontram-se na zona rural e 1.925 na zona urbana. A estrutura fundiária do município é caracterizada por pequenas propriedades familiares, sendo que $70 \%$ das propriedades têm menos de 20 ha, as quais ocupam apenas $20 \%$ da área total do município, o qual possui $622 \mathrm{~m}^{2}$.

Nas últimas décadas, os agricultores desta região passaram a dedicar-se cada vez mais à realização de atividades econômicas não agrícolas, entre elas o extrativismo de produtos florestais como a samambaiapreta. Os atores sociais que extraem este recurso são conhecidos localmente como "samambaieiros". As famílias de samambaieiros vivem nas encostas, em lotes pequenos de terra não apropriados a cultivos anuais. Em grande parte são formadas por agricultores tradicionais que não conseguiram se inserir no processo de modernização da agricultura que ocorreu em todo o país. Impossibilitados de adotar os pacotes tecnológicos impostos e, mais recentemente, balizados pela legislação ambiental restritiva em relação ao uso das capoeiras, estes agricultores adotaram as práticas extrativistas como uma alternativa de garantir sua reprodução social.(Anama 2002).

O extrativismo de samambaia-preta envolve cerca de 3.000 famílias do Litoral Norte do Rio Grande do Sul, sendo que atualmente é exercido pelas famílias mais jovens, uma vez que os mais idosos têm sua fonte de renda na aposentadoria rural. Muitos deles, antes da aposentadoria, foram extrativistas, sendo os pioneiros nesta atividade na localidade. Nos núcleos familiares onde a extração da samambaia é a principal fonte de renda, percebe-se que a atividade de coleta muitas vezes representa o ofício fixo das mulheres, enquanto os homens participam quando não há ofertas mais rentáveis tais como empreitadas, carpintaria e construção civil (Anama/PGDR-UFRGS 2003).

Coleta e análise dos dados - Os dados relacionados aos sistemas de manejo da samambaia-preta foram obtidos por meio de entrevistas semi-estruturadas. As entrevistas abordaram aspectos relacionados ao manejo da paisagem nas áreas de coleta e às práticas de manejo das populações de samambaia, procurando-se registrar o conhecimento associado a estas práticas. Através das entrevistas também se buscou a compreensão da evolução dos principais sistemas de manejo na região de estudo. Para a caracterização da atividade extrativista também foi utilizada a técnica da observação participante (Viertler 2002). Foram acompanhadas as etapas de coleta, transporte, armazenagem e confecção das unidades de comercialização de samambaia.

No município de Maquiné, o extrativismo de samambaia ocorre em grande parte das sub-bacias, não havendo registros apenas nas sub-bacias Pavão e Escangalhado (Baldauf et al. 2005). Desta forma, foram amostradas as doze sub-bacias com registro de atividade extrativista no município. O número de famílias extrativistas em cada sub-bacia foi definido a partir de informações locais, variando entre uma e treze 
famílias. O esforço amostral foi de pelo menos $20 \%$ das famílias por sub-bacia, visando atingir a representatividade geralmente utilizada em estudos que se valem de tipologias (Embrapa 1991; Miranda et al. 1995; Anama/PGDR-UFRGS 2000) e totalizando trinta entrevistas.

As informações obtidas nas entrevistas foram quantificadas usando estatísticas descritivas e, nos casos de comparações, foi usado o teste Mann-Whitney ( $\mathrm{p}<0,05)$. Também foram utilizadas técnicas de análise multivariada para ordenação dos extrativistas em relação às principais características dos sistemas de manejo empregados na região. As técnicas de ordenação multivariada permitem o estudo dos fatores que determinam a formação de grupos de similaridade (Peroni 2002). Em função da predominância de descritores binários foi utilizada a análise de correspondência a fim de verificar quais fatores interferem na formação de grupos distintos de extrativistas. Foram usados os programas SPSS (Statistical Package for Social Sciences) versão 10.0 (SPSS Inc.1999) e MVSP (Multivariate Statistical Package) versão 3.12 d (Kovach 2001).

Para caracterizar os sistemas de manejo utilizados no município de Maquiné foram previamente definidos descritores quantitativos e binários (Tab. 1). Os descritores que apresentaram correlações maiores que $0,60 \mathrm{com}$ os eixos principais um e dois foram considerados como variáveis discriminantes para a formação de uma tipologia dos sistemas de manejo da espécie na região de estudo.

\section{Resultados e discussão}

A atividade extrativista - A extração de samambaia é a atividade principal dos entrevistados (50\%), seguida da agricultura com $36,6 \%$. Os demais entrevistados atribuíram a mesma importância às duas atividades, exceto um deles cuja principal atividade é o trabalho de pedreiro. No entanto, os informantes que atualmente consideram a extração de samambaia como sua principal atividade, no passado se dedicavam à agricultura, mantendo hoje apenas pequenos cultivos para subsistência (Tab. 2). Estes valores estão de acordo com o trabalho de Ribas \& Miguel (2004), que apontaram que a maioria da população envolvida na extração da samambaia tem nesta atividade sua principal fonte de renda.

Conforme relatado pelos extrativistas mais antigos, na década de 1970 começou a ocorrer a vinda de coletores de samambaia procedentes de outras localidades do Rio Grande do Sul, que arrendavam áreas de capoeira dos moradores locais: "vinham em grupos e tiravam toda a samambaia". Em seguida, os próprios moradores passaram a coletar a samambaia para estas pessoas, ocorrendo uma especialização na cadeia produtiva com a presença de figura do atravessador ("puxador"), ou seja, aquela pessoa que recolhe as samambaias coletadas pelos moradores e entrega a outros intermediários.

Tabela 1. Descritores ecológicos utilizados na caracterização dos sistemas de manejo utilizados por extrativistas de samambaia-preta (Rumohra adiantiformis (G. Forst) Ching) do município de Maquiné, RS.

\begin{tabular}{|c|c|c|}
\hline Código do descritor & Natureza do descritor & Significado \\
\hline FCO & quantitativa/ discreta & Frequiência de corte utilizada por extrativista (número de cortes anuais/área) \\
\hline IAG & binária & $\begin{array}{l}\text { Interação com agricultura: área destinada aos cultivos é a mesma onde é realizada } \\
\text { a coleta de samambaia }\end{array}$ \\
\hline IGD & binária & $\begin{array}{l}\text { Interação com gado: área destinada à criação de bovinos é a mesma onde é } \\
\text { realizada a coleta de samambaia }\end{array}$ \\
\hline DER & binária & Realização de derrubada das capoeiras nas áreas de coleta de samambaia \\
\hline QUE & binária & Realização de queimadas nas áreas de coleta de samambaia \\
\hline POD & binária & Realização de podas e roçadas nas capoeiras das áreas de coleta de samambaia \\
\hline MSA & binária & $\begin{array}{l}\text { Realização de práticas de manejo das populações de samambaia (pisoteio das } \\
\text { áreas com samambaia após a coleta, retirada de frondes senescentes) }\end{array}$ \\
\hline SOR & binária & Coleta de frondes que apresentam soros (férteis) \\
\hline DAN & binária & Coleta de frondes que apresentam danos (sapecada, comida, torta...) \\
\hline DIN & binária & Diminuição ou suspensão da coleta do período do inverno \\
\hline BRO & binária & $\begin{array}{l}\text { Coleta durante o período de brotação da samambaia (fim do inverno/início da } \\
\text { primavera) }\end{array}$ \\
\hline QDU & binária & $\begin{array}{l}\text { Realização da prática de quebrar uma fronde em duas (ambos os pedaços são } \\
\text { colocados na mala de samambaia) }\end{array}$ \\
\hline
\end{tabular}


Tabela 2. Atividade principal, número de malas por coleta, número de coletas por semana e área manejada por extrativistas de samambaiapreta (Rumohra adiantiformis (G. Forst) Ching) do município de Maquiné, RS.

\begin{tabular}{|c|c|c|c|c|}
\hline $\mathrm{N}^{\mathrm{*} *}$ & Atividade $* *$ & Malas por coleta & Coletas/semana & Área manejada (ha) \\
\hline 1 & A & 250 & 2 & 12 \\
\hline 2 & A & 110 & 2 & 108 \\
\hline 3 & A & 100 & $5-6$ & 18 \\
\hline 4 & $\mathrm{~A}+\mathrm{S}$ & 250 & 2 & 24 \\
\hline 5 & $\mathrm{~A}$ & 80 & 1 & não sabe \\
\hline 6 & $\mathrm{~A}+\mathrm{S}$ & 100 & 1 & 25 \\
\hline 7 & $\mathrm{~S}$ & 250 & 7 & não sabe \\
\hline 8 & A & 200 & 2 & 80 \\
\hline 9 & A & 70 & 1 & 200 (não tem em toda área) \\
\hline 10 & A & 50 & 3 & 90 \\
\hline 11 & $\mathrm{~S}$ & 250 & 1 & 3 \\
\hline 12 & S & 200 & 2 & não sabe \\
\hline 13 & A & 120 & 1 & 15 \\
\hline 14 & $\mathrm{~S}$ & 200 & 3 & não sabe (5 propriedades) \\
\hline 15 & $\mathrm{~A}+\mathrm{S}$ & 100 & 2 & 12 \\
\hline 16 & $\mathrm{~S}$ & 100 & $3-4$ & 5000 \\
\hline 17 & S & 200 & 2 & 2,5 \\
\hline 18 & A & 80 & 1 & 2 \\
\hline 19 & A & 500 & 1 & "é pequena" \\
\hline 20 & A & 200 & 5 & não sabe \\
\hline 21 & S & 800 & 3 & não sabe \\
\hline 22 & S & 150 & 2 & 10 \\
\hline 23 & $S$ & 500 & 5 & não sabe \\
\hline 24 & S & 150 & $3-4$ & 40 \\
\hline 25 & S & 500 & 3 & "é bastante" \\
\hline 26 & S & 50 & 4 & 6 (“só manchas”) \\
\hline 27 & $\mathrm{P}$ & 80 & 4 & 15 ("só umas bolinhas") \\
\hline 28 & S & 800 & 6 & não sabe \\
\hline 29 & S & 500 & 7 & não sabe \\
\hline 30 & S & 100 & 3 & não sabe (arrenda várias propriedades) \\
\hline
\end{tabular}

$*$ Número referente a cada entrevistado; **Atividade principal informada pelo entrevistado: $\mathrm{A}=$ agricultor; $\mathrm{S}=$ samambaieiro; $\mathrm{A}+\mathrm{S}=\mathrm{considera}$ as duas atividades igualmente importantes; $\mathrm{P}=$ pedreiro

Atualmente, a coleta é efetuada em terras próprias e em terras arrendadas, sendo que $36,7 \%$ dos entrevistados coletam exclusivamente em terras próprias, $36,7 \%$ em terras arrendadas e $26,6 \%$ coletam em ambas. $\mathrm{O}$ arrendamento da terra pode ser anual ou o arrendatário pode pagar um percentual por quantidade comercializada, em geral entre 5 a $10 \%$ da renda bruta obtida com a venda da samambaia. Não foram encontradas situações como as descritas por Ribas et al. (2002), onde o valor do arrendamento atingia valores próximos a $30 \%$ da renda bruta oriunda da venda das frondes.

Em alguns casos, o proprietário cede uma dada área para extração sem cobrar nada ou em troca de algum serviço na propriedade. Uma outra situação, cada vez mais freqüente, é a relação entre samambaieiros e proprietários de sítios de lazer na região, onde os primeiros se comprometem a "cuidar da área" em troca do livre acesso à propriedade para coleta das frondes de $R$. adiantiformis. Os extrativistas consideram que a ocorrência da espécie está restrita aos estádios sucessionais iniciais, vindo a desaparecer na medida em que "a capoeira engrossa". São unânimes ao afirmar que "o que vai acabar com a samambaia não é o samambaieiro, é o capoeirão". Identificam como principais locais de coleta as áreas onde havia cultivos agrícolas (roças) no passado.

Os samambaieiros costumam manter trilhas abertas para acesso às áreas de coleta, nas quais ocorrem as "bolas" ou "malhas" de samambaia (áreas com alta densidade de frondes). Essas trilhas, muitas vezes também são locais de extração, visto que as roçadas periódicas favorecem a implantação e desenvolvimento de populações de samambaia, possivelmente a partir de uma maior entrada de luz. 
As malas são as unidades de comercialização da samambaia-preta na região, outrora formadas por quatro molhos de 15 frondes com as hastes cruzadas, totalizando 60 frondes. Recentemente, devido à desvalorização no preço do produto (Anama 2002), a saída encontrada pelos extrativistas foi diminuir o número de frondes em cada mala. Assim, a mala hoje é formada por cerca de 40-45 frondes, amarradas com barbante. Cada cem malas correspondem a um "milimol", o qual é vendido pelo preço médio de $\mathrm{R} \$ 45,00$.

São preferencialmente comercializadas frondes adultas, sem soros e sem danos. Contudo, apenas um dos entrevistados afirmou não coletar frondes com soros. Vários informantes destacam que "sempre vai um pouco de folha pintada no meio da mala". Os coletores também ressaltam que a quantidade de frondes com soros em cada mala está relacionada à época do ano. No inverno (menor disponibilidade de frondes) e também em períodos de grande demanda, como o dia das mães e o dia de finados, são comercializadas frondes com soros, assim como frondes com danos. Os informantes ainda destacam que, apesar dos puxadores não gostarem, muitos costumam quebrar uma fronde em duas e colocar no meio da mala. Esta é uma prática bastante corriqueira, realizada por $43,3 \%$ dos entrevistados.

O número de coletas por samambaieiro variou de uma a sete coletas por semana, tendo uma média de 2,9 vezes por semana $(s=1,7)$. Foi possível constatar uma associação entre a atividade principal (agricultura ou samambaia) desempenhada pelo entrevistado e o número de coletas por semana, sendo que, em grande parte dos casos, as maiores frequiências de coletas por semana são empregadas pelos informantes que têm como atividade principal a extração de samambaia.

Os entrevistados que declararam a agricultura como atividade principal coletam de uma até cinco vezes por semana, sendo que a maioria $(76,9 \%)$, coleta no máximo duas vezes por semana. Já entre os que consideram o extrativismo sua principal atividade, a maior parte $(66,6 \%)$ coleta entre duas a quatro vezes por semana. Neste último grupo, dois entrevistados afirmaram coletar todos os dias da semana, até mesmo no dia em que o atravessador vinha buscar. O número de coletas por semana apresentou diferenças significativas entre os grupos formados por agricultores e por samambaieiros $(U=67,5 ; p<0,05)$.

Os valores relativos ao número de malas comercializadas por semana por entrevistado se apresentaram bastante variáveis, sendo que a média encontrada foi de 234,7 malas/semana ( $\mathrm{s}=205,8$ ), em um universo que variou entre 50 e 800 malas. O teste Mann-Whitney também detectou diferença nesta característica, sendo que o grupo formado exclusivamente por samambaieiros extrai um número mais elevado (Tab. 2) de malas por coleta $(U=59,5$; $\mathrm{p}<0,05$ ).

Estes dados reforçam a idéia apresentada por Ribas \& Miguel (2004) de que os extrativistas que apresentam uma diversificada produção agrícola, tanto para autoconsumo como para venda, realizam uma exploração mais esporádica da samambaia-preta, ao passo que as pessoas que não desenvolvem praticamente nenhuma atividade agrícola destinada ao autoconsumo apresentam uma grande dependência econômica para com a atividade de extração.

As informações sobre o tamanho da área manejada também oscilaram bastante (Tab. 2). Tal variação pode ser decorrente da distribuição irregular das populações da espécie, bem como da existência de capoeiras em diferentes estádios de desenvolvimento ao longo das propriedades. Os valores informados muitas vezes correspondiam à área total da propriedade, sendo que todos os entrevistados ressaltavam que a samambaia só ocorria em parte da área.

No que se refere à frequiência de corte anual aplicada na mesma área pelos extrativistas entrevistados, 63,3\% realizam até três cortes, 23,3\% entre quatro e cinco cortes anuais e apenas $13,2 \%$ realizam cinco ou mais cortes por ano. Entende-se frequiência de corte como o número de vezes por ano que o extrativista coleta as frondes do mesmo local. O grupo formado por agricultores utiliza um número menor de cortes anuais do que os samambaieiros $(\mathrm{U}=50,5 \mathrm{p}<0,01)$. Os extrativistas mencionam ainda que existe uma sazonalidade que deve ser respeitada em relação à produtividade da área ("no inverno a samambaia só dá um corte e no verão dá dois"). Assim, no inverno a coleta diminui ou é suspensa para muitos extrativistas $(73,3 \%)$, os quais se dedicam a outras atividades neste período e/ou reduzem o número de coletas por semana. Uma pequena parte $(23,3 \%)$ dos coletores afirma não coletar no período de brotação da samambaia, geralmente compreendido entre agosto e setembro.

Apesar da samambaia-preta ser considerada ecologicamente como uma espécie pioneira, muitos entrevistados afirmam não realizar nenhuma intervenção na paisagem para manter as áreas produtivas, simplesmente procurando outros locais para 
exploração "quando a capoeira engrossa". Ao serem questionados sobre esta estratégia, eles relatam dois motivos principais: a legislação ambiental ("o Ibama") e o fato de não valer a pena, do ponto de vista econômico, gastar tanto tempo com esta atividade. Alguns extrativistas afirmaram realizar pequenas intervenções como podas e roçadas na vegetação para aumentar a incidência de luz nas áreas de coleta de samambaia-preta. Contudo, parte destes informantes relatou que já usou esta estratégia e não foi bem sucedida, uma vez que, após as podas, as árvores brotavam novamente, aumentando ainda mais a sombra sobre as populações de samambaia.

Uma associação evidenciada nas entrevistas é a extração de samambaia em áreas de pousio agrícola. Neste sistema, de maneira geral, as áreas em estádios sucessionais médios ou avançados (capoeirão) são desmatadas e queimadas no período do inverno e em seguida são implementados cultivos anuais (geralmente milho e feijão). Após a realização das colheitas, as áreas são deixadas em pousio.

Conforme os entrevistados, após um ano de abandono das áreas cultivadas, as malhas de samambaia começam a aparecer. Todavia, estes não consideram recomendável a coleta no primeiro ano, visto que neste período a samambaia estaria fraca e com frondes pequenas. De acordo com a maioria dos extrativistas, somente a partir do segundo ano de pousio que se torna possível começar a coletar as frondes sem prejudicar a planta.

Nestes casos, o manejo da paisagem é bastante intenso, pois se baseia no sistema tradicional de derrubada e posterior queima da vegetação da capoeira, mantido historicamente pelos agricultores da região. Conforme relatado pelos entrevistados, esta associação entre sistemas de cultivo de plantas anuais e extrativismo de samambaia já foi bem mais freqüente na região, diminuindo consideravelmente devido às restrições impostas pela legislação ambiental. Estas restrições também implicaram em uma redução das áreas cultivadas na região. Os agricultores-extrativistas que ainda praticam este sistema de manejo salientam que "derrubam só uma parte da área para botar roça, o resto deixam virar mato". Os entrevistados que não utilizam mais este sistema, implementam suas roças sempre no mesmo local, a fim de evitar a formação da capoeira. Este motivo também levou a redução do tempo de pousio das parcelas agrícolas, descaracterizando o sistema de agricultura tradicional.

Uma outra estratégia encontrada na região foi a extração de $R$. adiantiformis em áreas onde a capoeira foi substituída por pastagem para bovinos. Estas áreas são periodicamente queimadas e as "bolas" de samambaia aparecem durante a regeneração da vegetação.

Também foi verificada uma relação entre o tipo de manejo utilizado e a situação fundiária da propriedade onde a samambaia é coletada. Em geral, quando as terras utilizadas para a extração são arrendadas, a intervenção na paisagem é superficial, limitando-se a pequenos desbastes ou podas na vegetação. Já na extração em terras próprias, é possível encontrar sistemas de manejo da paisagem mais intensos, visto que muitas vezes a coleta de samambaia está inserida em um sistema agropastoril.

Além do manejo das áreas de capoeira nas quais são realizadas as coletas das frondes, também foi constatada a existência de práticas que visam assegurar ou intensificar a brotação de novas frondes, bem como garantir uma boa produtividade das áreas. Estas práticas são aqui denominadas de "práticas de manejo de populações de samambaia", sendo que as duas principais técnicas são o pisoteio das "bolas" de samambaia e a retirada de frondes senescentes após a coleta.

O pisoteio das "bolas" de samambaia geralmente é realizado imediatamente após a coleta. Após a retirada das frondes os extrativistas caminham por cima das áreas onde recém coletaram a fim de estimular a vinda de uma nova brotação. Já a retirada das frondes velhas após a coleta (realizada exclusivamente por mulheres) tem por objetivo "dar mais força" para a planta brotar novamente.

Análise de correspondência - Os três primeiros eixos produzidos pela análise de correspondência correspondem a 69,4\% da variação total dos dados. De acordo com Prado et al. (2002), quando os dois ou três primeiros eixos explicam grande parte da variação (60 a $90 \%$ ), torna-se possível usá-los para descrever todo o sistema sem grande perda de informação. Não foi procedida a interpretação do terceiro eixo, uma vez que este não apresenta descritores com correlações acima do valor mínimo estabelecido.

No eixo um a ordenação está associada aos descritores "freqüência de corte" (FCO), "realização de derrubadas" (DER), "realização de queimadas" (QUE) e "interação com agricultura" (IAG). Um primeiro agrupamento (13 entrevistados - grupo A) é formado por extrativistas que apresentaram valores mais altos de FCO e pouca associação com DER, QUE e IAG. Um segundo grupo (11 entrevistados - grupo B) 
é formado a partir da associação de alguns extrativistas com estes três últimos descritores e valores menores de FCO. Ainda ocorre a formação de um terceiro grupo (seis entrevistados - grupo C), este mais relacionado ao eixo dois, portanto associado aos descritores "realização de podas e roçadas na capoeira" (POD) e "realização de práticas de manejo das populações de samambaia" (MSA) (Fig. 1).

O grupo A é predominantemente composto por entrevistados cuja principal atividade é a extração de samambaia. É formado por extrativistas que não realizam nenhuma intervenção na paisagem para manter a produtividade da área (com exceção do entrevistado $n^{\circ} 26$ ), tampouco realizam algum manejo das populações da espécie. Os membros deste grupo utilizam as frequiencias de corte mais elevadas encontradas neste estudo (em média 4,9 cortes anuais, variando de dois até 12 cortes anuais em uma mesma área).

Ao serem questionados acerca do uso de um número mais elevado de cortes do que o empregado pela maioria dos coletores na região, os membros deste grupo respondem que estão cientes que uma alta frequiência de corte provoca o enfraquecimento do rizoma e a diminuição do tamanho das frondes, no entanto, alegam motivos de ordem econômica para fazê-lo. Além disso, alguns extrativistas associam uma

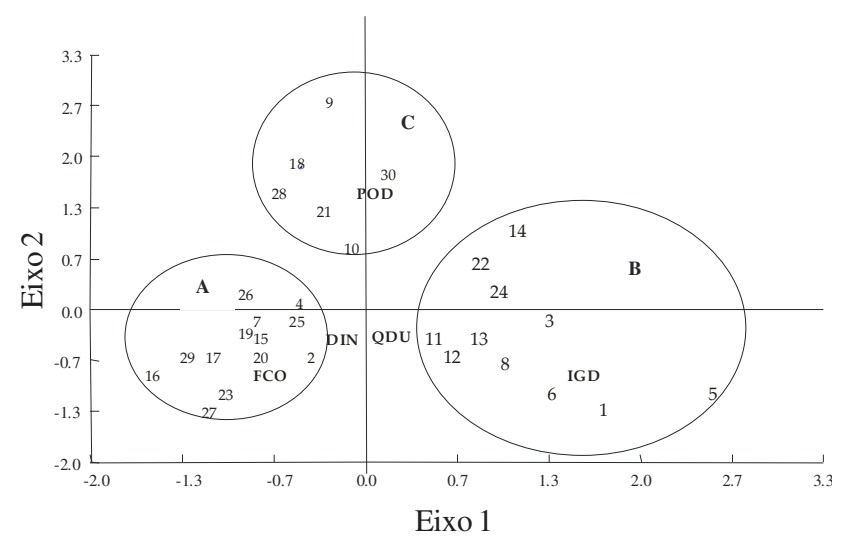

Figura 1. Diagrama de ordenação dos extrativistas e descritores dos sistemas de manejo de samambaia-preta (Rumohra adiantiformis (G. Forst) Ching) no município de Maquiné, RS produzido pela Análise de Correspondência, contendo os eixos 1 e 2. Os números representam os extrativistas entrevistados. FCO: frequiência de corte; IAG: interação com agricultura; IGD: interação com gado; DER: prática de derrubada; QUE: uso de queimadas; POD: uso de podas/roçadas; MSA: manejo das populações de samambaia; SOR: coleta de frondes férteis; DAN: coleta de frondes com danos; DIN: diminui coleta no inverno; BRO: diminui coleta na brotação; QDU: quebra a fronde em duas partes; A: grupo A; $\mathrm{B}$ : grupo B; C: grupo C (conforme texto). maior intensidade de coleta à existência de períodos de alta pluviosidade, nos quais a brotação seria mais rápida.

O grupo $\mathrm{B}$, associado aos descritores DER, QUE e IAG, evidencia a já mencionada interface do extrativismo com as práticas agrícolas, visto que a derrubada da capoeira e o uso do fogo estão associados ao sistema local de agricultura de coivara. Também é possível constatar um pequeno grupo de agricultores cuja atividade extrativista está associada à criação de gado (ainda que o descritor IGD não tenha sido utilizado na análise por apresentar valor inferior ao estabelecido).

Em relação ao eixo dois, ocorreu a formação do grupo $\mathrm{C}$, onde estão agrupados todos os extrativistas que realizam pequenas intervenções na paisagem (podas e roçadas) nas áreas onde coletam e/ou executam alguma prática de manejo das populações de samambaia, além de empregarem uma menor freqüência de cortes em uma mesma área (em média 2,9 , variando de 1 a 5 cortes anuais em uma mesma área).

Portanto, é possível afirmar que os sistemas de manejo de $R$. adiantiformis na região de estudo se diferenciam principalmente pelo manejo da paisagem (derrubadas, queimadas, podas e roçadas) e pelo uso de práticas de manejo nas populações de samambaia (técnicas como o pisoteio das malhas e retirada de frondes senescentes). Este cenário reflete a idéia de que o manejo de plantas pode ser entendido como resultado da integração de dois tipos de manipulação: a manipulação da vegetação em massa e a manipulação de plantas individuais (Alcorn 1991). Desta forma, no manejo da samambaia-preta são realizadas tanto intervenções em massa na capoeira (dentro do contexto da agricultura de coivara) quanto práticas de manipulação nas "bolas" de samambaia, sendo que estas últimas têm por finalidade promover uma maior regeneração das frondes da espécie. A intensidade e os tipos de manipulação das plantas e das paisagens servirão como elementos diferenciadores dos sistemas de manejo.

Tipologia dos sistemas de manejo - Com base nos resultados das entrevistas e da análise de correspondência foi elaborada uma tipologia dos sistemas de manejo de samambaia-preta. Cabe salientar que um extrativista pode se valer de mais de um sistema de manejo para explorar as populações de samambaia, sendo assim o resultado da soma das freqüências de cada sistema de manejo ultrapassa 100,0\%. A tipologia 
Tabela 3. Correlação dos descritores dos sistemas de manejo utilizados por extrativistas de samambaia-preta (Rumohra adiantiformis (G. Forst) Ching) no município de Maquiné, RS com os três primeiros eixos da ordenação produzida por Análise de Correspondência. Os valores em negrito foram utilizados na interpretação do eixo.

\begin{tabular}{|c|c|c|c|c|}
\hline Descritor & Significado & Eixo 1 & Eixo 2 & Eixo 3 \\
\hline QUE & Realização de queimadas nas áreas de coleta de samambaia & 0,78 & 0,02 & 0,09 \\
\hline IAG & Interação com agricultura & 0,69 & 0,06 & 0,06 \\
\hline DER & Realização de derrubada das capoeiras nas áreas de coleta de samambaia & 0,67 & 0,01 & 0,05 \\
\hline FCO & Freqüência de corte & 0,65 & 0,10 & 0,05 \\
\hline POD & Realização de podas e roçadas nas capoeiras das áreas de coleta de samambaia & $<0,01$ & 0,68 & 0,11 \\
\hline MSA & $\begin{array}{l}\text { Realização de práticas de manejo das populações de samambaia (pisoteio das malhas, } \\
\text { retirada de frondes senescentes) }\end{array}$ & 0,02 & 0,66 & $<0,01$ \\
\hline IGD & Interação com gado & 0,34 & 0,11 & 0,27 \\
\hline SOR & Coleta de frondes que apresentam soros (férteis) & $<0,01$ & 0,04 & 0,01 \\
\hline DAN & Coleta de frondes que apresentam danos (sapecada, comida, torta...) & 0,02 & 0,08 & $<0,01$ \\
\hline DIN & Diminuição ou suspensão da coleta do período do inverno & 0,04 & 0,01 & 0,23 \\
\hline $\mathrm{BRO}$ & Coleta durante o período de brotação da samambaia & 0,01 & 0,02 & 0,11 \\
\hline QDU & Realização da prática de quebrar uma fronde em duas & $<0,01$ & 0,11 & 0,56 \\
\hline
\end{tabular}

dos sistemas de manejo de $R$. adiantiformis empregados no município de Maquiné é descrito a seguir:

a) Sistema de manejo um (SM1): utilizado por 40,0\% dos entrevistados. Neste sistema, o extrativista praticamente não intervém na paisagem para manter a produção das áreas onde se localizam as populações de samambaia. As intervenções limitam-se à coleta das frondes e a roçadas eventuais para manutenção das trilhas. Também não são realizadas práticas de manejo nas populações de samambaia. Ocorre tanto em terras próprias como arrendadas e é realizado principalmente pelos informantes que consideram a extração de samambaia como sua atividade principal, sendo também caracterizado pela aplicação das freqüências de corte mais elevadas.

b) Sistema de manejo dois (SM2): utilizado por 20,0\% dos entrevistados. O manejo da paisagem onde são feitas as coletas é realizado através de podas de algumas árvores e roçadas na capoeira. Neste sistema também são realizadas técnicas de manejo das populações, as quais visam estimular a brotação da samambaia. As técnicas utilizadas são a retirada de frondes senescentes e o pisoteio das malhas de samambaia durante e após a coleta.

Este sistema é empregado predominantemente pelos extrativistas que coletam em terras próprias, ocorrendo mais raramente em terras arrendadas. A freqüência de corte utilizada é intermediária, sendo o valor mais comum o de três cortes anuais.

c) Sistema de manejo três (SM3): é usado por 30,0\% dos informantes. Este sistema é baseado na agricultura de coivara, caracterizada pela derrubada e posterior queima da vegetação para implantação de cultivos anuais. Após alguns ciclos de cultivo, é iniciado o período de pousio, no qual ocorre a extração da samambaia. Geralmente, a coleta da fronde é iniciada a partir do segundo ano de pousio e pode ter continuidade por vários anos, até que a ocorrência da espécie comece a diminuir, devido ao excesso de sombreamento. O SM3 é utilizado exclusivamente em terras próprias, onde a paisagem é formada por mosaicos de vegetação em diferentes estádios sucessionais e apresenta as menores freqüências de corte empregadas na região. Uma variante deste sistema é empregada por um dos informantes. Nesta variação a exploração da samambaia só inicia no quarto ano de pousio e a coleta das frondes é realizada somente no período do inverno, época em que existe grande demanda pela espécie.

d) Sistema de manejo quatro (SM4): este sistema, utilizado por $16,6 \%$ dos extrativistas, está centrado na criação de bovinos enquanto estratégia para impedir o estabelecimento do processo de sucessão florestal. Assim como no sistema anterior, as áreas com capoeira grossa são derrubadas, queimadas e neste caso, substituídas por pastagem perene para o gado. Estas parcelas são queimadas de forma periódica e a samambaia é extraída durante a regeneração da área. O SM4 é implementado exclusivamente em terras próprias, sendo que são utilizadas tanto freqüências baixas (1-2 cortes anuais), quanto frequiências relativamente altas (até cinco cortes anuais) de coleta das frondes. 
Apesar da análise de correspondência ter demonstrado a formação de um único grupo que abrange os sistemas de manejo classificados como três e quatro, optou-se por diferenciar estes dois sistemas. Ambos se valem da derrubada da capoeira e do uso do fogo, porém, esta divisão proposta baseia-se no argumento apresentado por Fox (2000) de que o sistema de agricultura de coivara difere consideravelmente da prática de usar o fogo para implementar cultivos permanentes ou pastagens, visto que nestes últimos o processo sucessional é completamente estancado. Estas características e suas influências na paisagem e nas populações de samambaia reforçam a necessidade da existência de um sistema distinto de manejo (SM4) na tipologia apresentada.

Segundo Anderson (1990), freqüentemente as populações rurais têm o conhecimento e o respeito pelos recursos florestais necessários para que haja a conciliação entre o extrativismo e o manejo florestal, o que torna a atividade sustentável do ponto de vista ecológico. Este parece ser o caso do extrativismo de samambaia-preta no Litoral Norte, RS. De acordo com estudos realizados por Anama (2002), a frequiência de corte recomendada para a área de estudo é de até três cortes por ano em cada área explorada. Os dados do presente trabalho demonstram que grande parte dos extrativistas $(63,3 \%)$ realiza até três cortes anuais, $23,3 \%$ realizam entre quatro e cinco cortes e apenas $13,2 \%$ realizam cinco ou mais cortes por ano.

No caso da coleta das frondes de samambaiapreta, a implementação de alguns sistemas com frequiência de corte elevada sugere que existe um hiato entre o conhecimento local e as práticas de manejo utilizadas na região. Quando questionados, acerca destas práticas, grande parte dos extrativistas afirma "saber que estão errados" e destacam principalmente razões de ordem econômica para proceder desta forma. Sobre este fato, vale lembrar que não são simplesmente as limitações ambientais que motivam um tipo específico de exploração dos recursos naturais, mas sim as formas com que se configuram as relações sociais, suas racionalidades intencionais, seus objetivos de produção material e social (Diegues 1996).

Verificou-se ainda que a utilização de alguns sistemas de manejo descritos encontra-se em declínio avançado, principalmente aqueles baseados no sistema de agricultura de coivara. Contudo, a sua caracterização, além de fornecer informações importantes sobre os fatores que os levaram a essa situação, serve como um alerta para sensibilizar o poder público da necessidade de implementação de políticas que contemplem as atividades dos agricultores familiares no meio rural. Destaca-se aqui a necessidade de pensar o manejo da samambaia dentro do contexto do manejo de uma paisagem (capoeira), a qual desempenha um papel fundamental tanto na regeneração florestal, quanto no sistema produtivo local.

Foi constatada a existência de uma diversidade de práticas de manejo relacionadas ao extrativismo de samambaia-preta no município de Maquiné, RS. Estas práticas constituem sistemas de manejo distintos e foram agrupadas em uma tipologia. Nesta tipologia foram identificados quatro sistemas de manejo principais, os quais se diferenciam em função do manejo da paisagem e das técnicas de manejo de populações utilizados.

A tipologia apresentada neste trabalho vem fundamentando o processo de regulamentação da atividade extrativista no Rio Grande do Sul. A samambaia-preta foi o primeiro produto florestal nãomadeireiro (PFNM) a ter sua coleta e comercialização regulamentada neste estado, através da recente instrução normativa $n^{\circ}$ 001/06 da Secretaria Estadual do Meio Ambiente, publicada no Diário Oficial do dia 21 de novembro de 2006. Na construção desta instrução normativa foi considerada a diversidade do conhecimento local e práticas associadas ao manejo da espécie $R$. adiantiformis, reforçando o papel da etnobotânica na elaboração de estratégias de manejo de populações naturais. Ressalta-se ainda a construção coletiva desta regulamentação, a qual incorporou o conhecimento e as sugestões dos extrativistas e intermediários do comércio da samambaia.

A regulamentação do extrativismo da samambaiapreta no Rio Grande do Sul, além de retirar os samambaieiros da situação de ilegalidade, possibilitará o início de sua organização social enquanto extrativistas. A legalização também traz consigo uma possibilidade de melhor estruturação da cadeia produtiva, a qual deve ter como prioridade uma remuneração mais justa a estes atores sociais. Finalmente, destaca-se que a manutenção do extrativismo desta espécie é de suma importância, uma vez que sua coleta representa uma das únicas alternativas que restaram hoje para aqueles que não conseguiram se inserir no contexto da modernização da agricultura ou que por diversos fatores não puderam mais preservar o "modo antigo de produzir": "Tirar samambaia é, por assim dizer, a minha profissão, é o que eu sei fazer bem... Me criei tirando samambaia. Se dependesse de mim, criaria 
meus filhos e ensinaria eles como tirar certinho, o jeito, a época certa..." (S.D., 42 anos.)

\section{Agradecimentos}

Aos extrativistas entrevistados, pela confiança e aprendizado proporcionado; a ONG Anama (Ação Nascente Maquiné), pelo apoio em campo; ao Nivaldo Peroni, pelo auxílio nas análises multivariadas; à Capes e ao CNPq, pelo suporte financeiro.

\section{Referências bibliográficas}

Alcorn, J. 1991. Huastec noncrop resource management: Implications for prehistoric rain forest management. Human Ecology 9(4): 395-417.

Amorozo, M.C.M. 1996. Abordagem etnobotânica na pesquisa de plantas medicinais. Pp. 47-68. In: L.C. Di Stasi (ed.). Plantas medicinais: arte e ciência. Um guia de estudo interdisciplinar. São Paulo, Unesp.

Anderson A.B. 1990. Extraction and forest management by rural inhabitants in the Amazon estuary. Pp. 65-85. In: A.B. Anderson (ed.). Alternatives to deforestation: steps toward sustainable use of the Amazon rain forest. New York, Colombia University Press.

Anama/PGDR-UFRGS. 2000. Diagnóstico socioeconômicoambiental do município de Maquiné, RS: perspectivas para um desenvolvimento rural sustentável. Relatório de Pesquisa. Porto Alegre, Fundação de Amparo à Pesquisa do Estado do Rio Grande do Sul.

Anama. 2002. Projeto Samambaia-preta: avaliação etnobiológica e etnoecológica da samambaia-preta Rumohra adiantiformis (G. Forst.) Ching no município de Maquiné, RS. Relatório Final. Porto Alegre, Secretaria Estadual do Meio Ambiente do Estado do Rio Grande do Sul.

Anama/PGDR-UFRGS. 2003. Avaliação etnobiológica e socioeconômica da samambaia-preta Rumohra adiantiformis (G. Forst) Ching na região da Encosta Atlântica do Estado. Relatório Final. Porto Alegre, Secretaria de Agricultura e Abastecimento do Estado do Rio Grande do Sul.

Baldauf, C.; Hanazaki, N. \& Reis, M.S. Caracterização dos sistemas de manejo de samambaia-preta: fundamentos para o licenciamento e monitoramento ambiental. Pp. 121-131. In: Anais de la XIII Jornadas de Jóvenes Investigadores de AUGM. Tucumán, Associación de Universidades Grupo Montevideo.

Balée, W. 1994. Footprints of the forest: Ka'apor ethnobotany - the historical ecology of plant utilization by an amazonian people. New York, Columbia University Press.

Berkes, F.; Kislaiolglu, M.; Folke, C. \& Gadgil, M. 1998. Exploring the basic ecological unit:ecosystem-like concepts in traditional societies. Ecosystems 1: 409-415.
Clement, C. 1999. 1492 and the loss of Amazoniam crop genetic resources. I. The relation between domestication and human population decline. Economic Botany 53(2): 188-202.

Clement, C. 2006. A lógica do Mercado e o futuro da produção extrativista. Pp. 135-150. In: R.R. Kubo; J.B. Bassi; G.P.C. Souza; N.L. Alencar; P.M. Medeiros \& U.P. Albuquerque (orgs.). Atualidades em etnobiologia e etnoecologia. v.3. Recife, Nupeea/SBEE.

Diegues, A.C. 1996. O mito moderno da natureza intocada. São Paulo, Hucitec.

Diegues, A.C. \& Arruda, R.A. 2001. Saberes tradicionais e biodiversidade. Brasília, Ministério do Meio Ambiente.

Diegues, A.C. 2002. Aspectos sociais e culturais do uso dos recursos florestais da Mata Atlântica. Pp. 135-158. In: L.L. Simões \& C.F. Lino (orgs.). Sustentável Mata Atlântica - A exploração de seus recursos florestais. São Paulo, Senac.

Hanazaki, N.; Tamashiro, J.Y.; Leitão Filho, H.F. \& Begossi, A. 2000. Diversity of plant uses in two Caiçara communities from the Atlantic Forest coast, Brazil. Biodiversity and Conservation 9: 597-615.

Instituto Brasileiro de Geografia e Estatística. 2000. Dados do censo demográfico.

Kovach, W.L. 2001. MVSP - A Multivariate Statistical Package for Windows, version 3.12d. Wales, Kovach Computing Services Pentraeth.

Milton, S.J. \& Moll, E.J. 1988. Effects of harvesting on frond production of Rumohra adiantiformis (Pteridophita: Aspidiaceae) in South Africa. Journal of Applied Ecology 25: 725-743.

Myers, N.; Mittermeier, R.A.; Mittermeier, C.G.; Fonseca, G.A.B. \& Kent, J. 2000. Biodiversity hotspots for conservation priorities. Nature 403: 854-858.

Peroni, N. 2002. Coleta e análise de dados quantitativos em etnobiologia: introdução ao uso de métodos multivariados. Pp. 155-180. In: M.C.M. Amorozo; L.C. Ming \& S.P. Silva (eds.). Métodos de coleta e análise de dados em etnobiologia, etnoecologia e disciplinas correlatas. Rio Claro, Divisa Gráfica Editora.

Posey, D.A. 1987. Manejo da floresta secundária, capoeiras, campos e cerrados Kayapó. Pp. 173-185. In: B.R. Ribeiro (coord.). Suma etnológica brasileira. Petrópolis, Vozes/ Finep.

Prado, P.I.; Lewinsohn, T.M; Carmo, R.L. \& Hogan, D.H. 2002. Ordenação multivariada na ecologia e seu uso em ciências ambientais. Ambiente \& Sociedade 10: 1-15.

Reis, M.S. 1996. Manejo sustentado de plantas medicinais em ecossistemas tropicais. Pp. 198-215. In: L.C. Stasi (ed.). Plantas medicinais: arte e ciência - Um guia de estudo interdisciplinar. São Paulo, Unesp.

Reis, M.S.; Conte, R.; Nodari, R.O.; Fantini, A.C.; Reis, A.; Mantovani, A. \& Mariot, A. 2000. Pp. 202-224. In: Manejo sustentável e produtividade do palmiteiro (Euterpe edulis Martius Arecaceae). In: Euterpe edulis Martius - (palmiteiro): biologia, conservação e manejo. M.S. Reis \& A. Reis (eds.). Itajaí, Herbário Barbosa Rodrigues. 
Ribas, R.P.; Guimarães, L.A.; Miguel, L.A.; Dourado, A.C.B.; Kubo, R.R. \& Coelho De Souza, G.P. 2002. Aspectos Econômicos E Sociais Da Cadeia Produtiva Da Samambaia-Preta (Rumohra adiantiformis (G. Forst.) Ching) Na Região Da Encosta Atlântica Do Estado Do RS. Redes 7(2): 153-166.

Ribas, R.P. \& Miguel, L.A. 2004. Extração e comercialização de folhagens ornamentais da Mata Atlântica: o caso da verdes (Rumohra adiantiformis) no RS. Revista de Economia e Sociologia Rural 42(4): 575-596.
Sevegnani, L. \& Batista, L.R.M. Composição florística de uma floresta secundária, no âmbito da Floresta Atlântica, Maquiné, RS. Sellowia 25: 47-71.

Spss Inc. 1999. Spss Version 10. Chicago, SPSS Inc.

Viertler, R.B. 2002. Métodos antropológicos como ferramenta para estudos em etnobiologia e etnoecologia. Pp. 11-30. In: M.C.M. Amorozo; L.C. Ming \& S.P. Silva (eds.). Métodos de coleta e análise de dados em etnobiologia, etnoecologia e disciplinas correlatas. Rio Claro, Divisa Gráfica Editora. 